\title{
Low haemoglobin levels increase unilateral spatial neglect in acute phase of stroke
}

\author{
Níveis baixos de hemoglobina aumentam a negligência espacial unilateral na fase aguda \\ do acidente vascular cerebral
}

\author{
Gustavo José Luvizutto', Tamiris Aparecida Monteiro", Gabriel Pereira Braga², \\ Silméia Garcia Zanati Bazan ${ }^{3}$, Luiz Antônio de Lima Resende ${ }^{4}$, Rodrigo Bazan ${ }^{4}$
}

\begin{abstract}
Objective: The objective of this study was to evaluate the relationship between unilateral spatial neglect (USN) and haemoglobin (Hb) level in acute phase of stroke. Method: Cross-sectional study was performed after right hemisphere ischemic stroke. Independent variable: Hb level (mg/dL); Outcome: USN; Potential confounding factors: Age, National Institutes of Health Stroke Scale (NIHSS), and glycaemia $(\mathrm{mg} / \mathrm{dL})$; Characterization variables were obtained from electronic medical records, $\mathrm{Hb}$, mean corpuscular volume (MCV) and glycaemia by laboratory exams, and USN by cancellation and bisection tasks. The relationship between Hb and USN was assessed by Spearman correlation and linear regression model. Results: 40 individuals were evaluated; it was observed that the higher the Hb level, the better the USN test performance, with the two being negatively correlated. There was no significant correlation between VCM level and USN performance. Conclusion: Low hemoglobin levels may indicate a worse performance in USN cancellation and bissection tests in acute phase of stroke.
\end{abstract}

Keywords: stroke, perceptual disorders, haemoglobins.

RESUMO

Objetivo: 0 objetivo do estudo foi avaliar a relação entre a negligência espacial unilateral (NEU) e hemoglobina (Hb) na fase aguda do acidente vascular cerebral (AVC). Método: Foi realizado estudo transversal em pacientes com AVC de hemisfério direito dentro das primeiras 48 horas do ictus. Variáveis independentes: nível de Hb (mg/dL); Desfecho: NEU; Fatores potenciais de confundimento: Idade, National Institutes of Health Stroke Scale (NIHSS) e glicemia (mg/dL); A caracterização das variáveis foram obtidas por meio de prontuários eletrônicos, Hb e glicemia por exames laboratoriais, e NEU por meio do Line Cancellation (LCT), Star Cancelation (SCT), e Line Bisection Tasks (LBT). Resultados: 40 indivíduos foram avaliados e foi observado que quanto maior os níveis de Hb, melhor o desempenho nos testes de NEU, demonstrando correlação negativa entre eles. Conclusão: Níveis baixos de hemoglobina podem indicar pior desempenho nos testes de NEU na fase aguda do AVC.

Palavras-chave: acidente vascular cerebral, transtornos da percepção, hemoglobinas.

Low haemoglobin $(\mathrm{Hb})$ is a common condition in the elderly population and is associated with increased mortality and worsening functional performance, independent of cause $^{1,2}$. Many people in acute phase of stroke present low haematocrit levels, which are associated with higher mortality and worsening long-term results; but the importance of low haemoglobin in stroke clinical presentation has not been clearly established ${ }^{3,4,5,6,7}$.
Currently, interest is growing in the effects of $\mathrm{Hb}$ concentration on cognitive decline. Critical Hb levels, high or low, have been associated with worsening cognitive performance in the elderly, but their mechanisms are poorly understood, with the hypothesis of the presence of ischemia, hypoxia or central nervous system oxidative stress $^{8,9}$. Based on the results of several studies, there is speculation that reduced aerobic capacity and cerebral vascular dysfunction could

`Seção Técnica de Reabilitação, Departamento de Neurologia, Faculdade de Medicina, Universidade Estadual Paulista “Júlio de Mesquita Filho”, Sao Paulo SP, Brazil;

Unidade de AVC, Departamento de Neurologia, Faculdade de Medicina, Universidade Estadual Paulista "Júlio de Mesquita Filho", Sao Paulo SP, Brazil; ${ }^{3}$ Departamento de Clínica Médica, Faculdade de Medicina, Universidade Estadual Paulista "Júlio de Mesquita Filho", Sao Paulo SP, Brazil; “Departamento de Neurologia, Faculdade de Medicina, Universidade Estadual Paulista "Júlio de Mesquita Filho”, Sao Paulo SP, Brazil.

Correspondence: Gustavo José Luvizutto; Faculdade de Medicina, Departamento de Neurologia; Distrito de Rubião Júnior, s/n; $18618-970$ Botucatu SP, Brasil; E-mail: gluvizutto@fmb.unesp.br

Conflict of interest: There is no conflict of interest to declare.

Received 23 August 2013; Received in final form 12 June 2014; Accepted 11 July 2014 
also contribute to cognitive decline, and that normal haematocrit levels reduce the transfer velocity within cerebral capillaries, improve oxygen extraction by cerebral tissue, and have a positive effect on cortex functions ${ }^{10,11}$.

In the present study, we evaluated the relationship between Unilateral Spatial Neglect (USN) by means of cognitive with perception tests, haemoglobin $(\mathrm{Hb})$ and mean corpuscular volume (MCV) level in acute phase of stroke. The study hypothesizes that low haemoglobin values are associated with poorer performance on tests of unilateral spatial neglect, given that anaemia may influence the performance of activities that place high demands on the perceptual system, increasing errors on tests of cancelling and bisection of lines.

\section{METHOD}

This was cross-sectional study of ischemic stroke patients of both sexes presenting with right hemisphere lesion - confirmed by cranial computerized tomography (CT) or magnetic resonance imaging (MRI) - of anterior circulation origin, with defined aetiology, in the acute ictus phase (in the first 48 hours after ictus), under conservative treatment and admitted to the Stroke Unit at Botucatu Medical School University Hospital - Universidade Estadual Paulista "Júlio de Mesquita Filho". Patients were excluded if they presented at least one of the following conditions: haemorrhagic or posterior circulation stroke, left hemisphere ischemia, previous Modified Rankin Scale $(\mathrm{mRS}) \geq 1$, preexisting dementia, aphasia, visual deficits, other neurological diseases, as were patients who had undergone surgical procedures, thrombolytic treatment, blood transfusion or presented a history of alcohol abuse, hypothyroidism, chronic obstructive pulmonary disease, liver disease, kidney failure or marked leukocytosis on laboratory exams.

\section{Procedures}

Individuals were evaluated through three USN exams, two for cancellation and one for bisection: a) Cancellations tests: Line Cancellation Task (LCT), scored by lines cancelled in relation to a total number of 40 lines on a sheet of paper ${ }^{12}$; Star Cancellation Task (SCT), scored by 52 stars cancelled in between distractors ${ }^{13}$; b) Bisection test: Line Bisection Task (LBT), based on the number of deviations to the right in relation to middle of line marked by patient on each line of the sheet ${ }^{14}$. In all USN tests the examiner placed the test sheet in front of the patient with the centre of the sheet $50 \mathrm{~cm}$ from the glabella, the objective being to measure USN severity.

$\mathrm{Hb}$ level (in g/dL), MCV (in fL) and other laboratory exams were performed through a standard protocol by nurses trained in vein puncture to collect blood samples using a sterile technique. The blood sample was collected in a $10 \mathrm{ml}$ tube on the same day that USN tests were applied, and transferred to the clinical laboratory for automated processing. After analysis of the exams, anaemia was defined as $\mathrm{Hb}<12 \mathrm{~g} / \mathrm{dL}$ in women and $\mathrm{Hb}<13 \mathrm{~g} / \mathrm{dL}$ in $\mathrm{men}^{15}$. The individuals classified as anaemic were divided into microcytic $(\mathrm{MCV}<80 \mathrm{fL})$, normocytic $(\mathrm{MCV}=80-100)$ or macrocytic $(\mathrm{MCV}>100 \mathrm{fL})^{16}$.

The National Institutes of Health Stroke Scale (NIHSS) and mRS were applied simultaneously with the USN tests to define neurological deficit severity and functional independence; demographic and anthropometric data were obtained from electronic hospital records on the same USN test date.

\section{Statistical analysis}

The relationship between potential confounding factors (age, sex, neurological deficit severity, functional independence and glycaemia) and USN was assessed by the Spearman correlation and Mann-Whitney test, whereas the relationship between $\mathrm{Hb}$ level, MCV and NSU was explored by the Spearman correlation and linear regression model. Significance was set at $p$ less than .05. Statistical analyses were performed using the software SPSS v.15.0.

\section{Ethics}

The study was approved by Human Research Ethics Committee of UNESP/Botucatu. All individuals or relatives consented to participate in the study.

\section{RESULTS}

One hundred and forty consecutive patients with stroke admitted to our University Hospital between June and December 2012, and a total of 40 patients were included in present data. The general demographic data and baseline characteristics are displayed in Table 1 , and the potential confounders are presented in Table 2.

Figures 1 and 2 show the negative correlation between $\mathrm{Hb}$ and LCT ( $\mathrm{r}=-0.35 ; \mathrm{p}=0.02)$ and SCT $(\mathrm{r}=-0.27 ; \mathrm{p}=0.09)$. The relationship between $\mathrm{Hb}$ level and USN evaluated by LBT (Figure 3) reveals its negative correlation with the number of deviations to the right $(r=-0.36 ; p=0.03)$. These associations were independent of age, sex, neurological deficit, incapacity level or blood glucose.

In the linear regression model, it was demonstrated that the higher the $\mathrm{Hb}$ level, the fewer lines and starswere cancelled, with an average of around three lines $(\beta=-3.1)$ and three stars $(\beta=-3.2)$ left un-cancelled for each unit increase in $\mathrm{Hb}$ (Tables 3 and 4).

Table 5 demonstrates an absence of a statistically significant correlation between the VCM level and the degree of unilateral spatial neglect by means of LCT ( $\mathrm{r}=-0.089$; $\mathrm{p}=0.616)$, SCT $(\mathrm{r}=0.001 ; \mathrm{p}=0.997)$ and LBT $(\mathrm{r}=0.063 ; \mathrm{p}=0.723)$. 
Table 1. Sample description.

\begin{tabular}{lc}
\hline Variable* & Value \\
\hline Age, y & $66(34-87)$ \\
Sex, male & $25(62.5 \%)$ \\
Race, White & $23(57.5 \%)$ \\
Weight $(\mathrm{Kg})$ & $72.4(43.8-99.0)$ \\
Height $(\mathrm{m})$ & $1.69(1.50-1.78)$ \\
BMI $\left(\mathrm{Kg} / \mathrm{m}^{2}\right)$ & $23.5(16.4-38.2)$ \\
NIHSS & $5(3-12)$ \\
mRS & $3(0-4)$ \\
Laboratory Exams & \\
Glycaemia, mg/dL & $101.5(69.0-237.0)$ \\
Urea, mg/dL & $20(12.0-37.0)$ \\
Creatinine, mg/dL & $0.8(0.5-1.2)$ \\
Haemoglobin, mg/dL & $14.1(8.6-16.9)$ \\
MCV, fl & $91.4(66.9-116.0)$ \\
USN exams & \\
$\quad$ Score on LCT & $15.5(0-36)$ \\
Score on SCT & $33.5(4-51)$ \\
Score on LBT & \\
$\quad$ Deviation from centre line & \\
*Numbers are mean (SD) or counts (percentages). BMI: Indicates body \\
mass index; mRS: Modified rankin scale; NIHSS: National Institutes of \\
Health Stroke scale; MCV: Mean corpuscular volume; USN: Unilateral \\
spatial neglect; LCT: Line cancellation task; SCT: Star cancellation task; \\
LBT: Line bisection task.
\end{tabular}

\section{DISCUSSION}

In our study we found a relationship between $\mathrm{Hb}$ level and the presence or absence of USN, and that age, sex, severity (NIHSS), incapacity (mRS) and glycaemia are not confounding factors in the final NSU result. This result is consistent with a physiological mechanism, as the much lower haemoglobin levels reduce cerebral oxygen, and thus worsen USN in the acute phase by establishing a larger area of ischemic penumbra and delimiting the lesion area much earlier ${ }^{8}$. Studies have shown that erythropoietin levels have neuroprotective properties that can regulate some caspases, and therefore prevent neuron death, which is important for reducing the ischemic area and improving neurological deficits $^{17}$.

Table 2. Relationship between age, neurological deficit and glycaemia as potential confounders for NSU.

\begin{tabular}{lcccc}
\hline Variable* & & LCT & SCT & LBT \\
\hline Age, $y$ & $r$ & 0.20 & 0.18 & 0.19 \\
& $p^{(1)}$ & 0.339 & 0.391 & 0.375 \\
NIHSS & $r$ & -0.19 & -0.22 & -0.32 \\
& $p^{(1)}$ & 0.402 & 0.332 & 0.155 \\
mRS & $r$ & 0.32 & 0.35 & 0.30 \\
& $p^{(1)}$ & 0.134 & 0.090 & 0.155 \\
Glycaemia $(\mathrm{mg} / \mathrm{dL})$ & $\mathrm{r}$ & -0.07 & -0.11 & 0.06 \\
\hline
\end{tabular}

*Numbers are mean (SD) or counts (percentages); (1) p-value associated with Spearman's correlation; r: estimate of Spearman's correlation. NIHSS: Indicates National Institutes of Health Stroke Scale; mRS: Modified Rankin scale; LCT: Line cancellation test; SCT: Star cancellation test; LBT: Line bisection test.

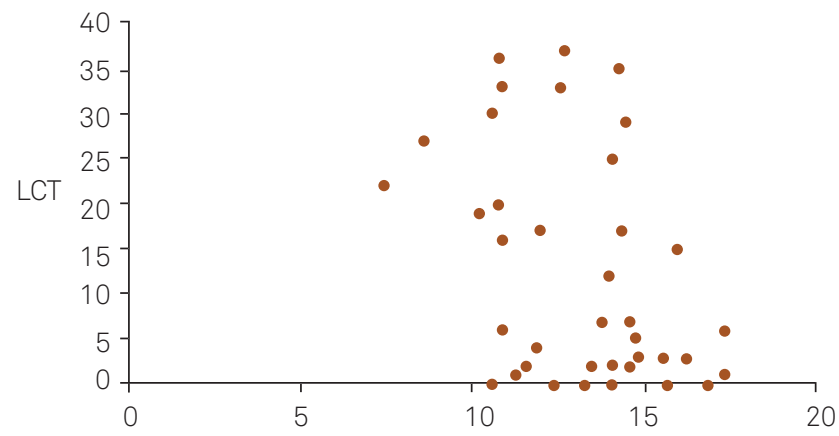

Hemoglobins

Figure 1. Correlation between Hemoglobins $(\mathrm{Hb})$ level and Line Cancellation Task (LCT).

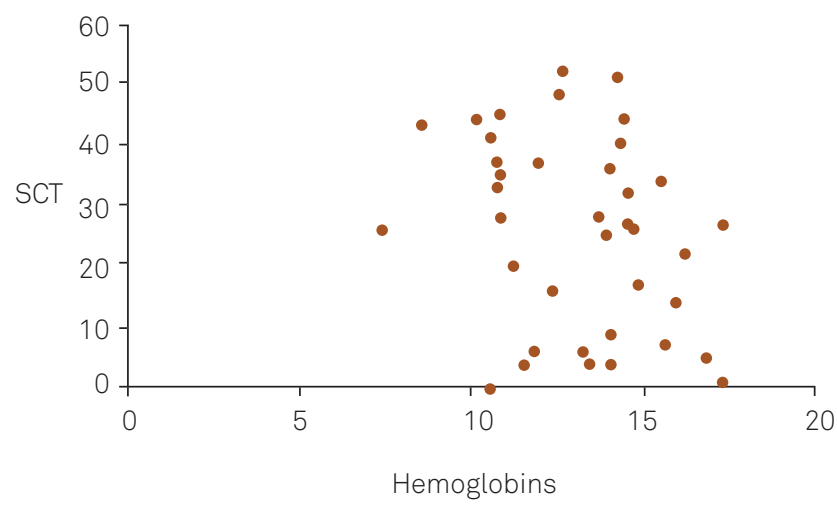

Figure 2. Correlation between Hemoglobins ( $\mathrm{Hb}$ ) level and Star Cancellation Task (SCT).

In the first study where this association was found, a "U" pattern was suggested in the correlation between $\mathrm{Hb}$ and USN, where the critical levels, high or low, had determined worse $\mathrm{USN}^{3}$. Our results highlight the drop in $\mathrm{Hb}$ in the acute phase as a factor of severity and cognitive decline as measured by the USN tests. In an observational study ${ }^{6}$, the authors reported that anaemia in stroke acute phase results in worse functional performance in the first three months

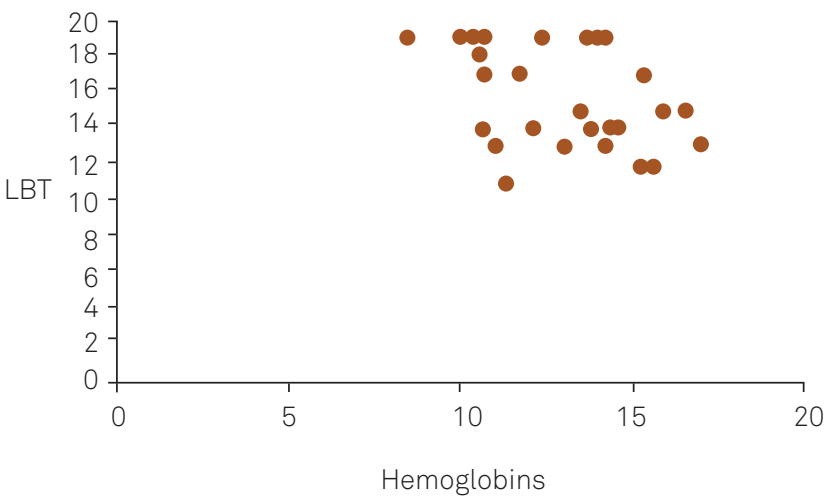

Figure 3. Correlation between Hemoglobins $(\mathrm{Hb})$ level and Line Bisection Task (LBT). 
Table 3. Linear regression models to explain the number of lines cancelled in LCT as a function of haemoglobin.

\begin{tabular}{lcccc}
\hline & $\beta$ & Standard error & $p$ & $\mathrm{Cl}(\beta: 95 \%)$ \\
\hline Constant & 56.2 & 15.1 & 0.001 & $(24.9-87.4)$ \\
Haemoglobin $(\mathrm{mg} / \mathrm{dL})$ & -3.1 & 1.1 & 0.010 & $(-5.4--0.8)$ \\
\hline
\end{tabular}

Residual analysis: $p=0.591$ (Shapiro-Wilk); LCT: Line cancellation task.

Table 4. Linear regression models to explain the number of stars cancelled in SCT as a function of haemoglobin.

\begin{tabular}{lcccc}
\hline & $\beta$ & Standard error & $\mathrm{p}$ & $\mathrm{Cl}(\beta: 95 \%)$ \\
\hline Constant & 71.3 & 17.3 & 0.001 & $(35.6-107.0)$ \\
Haemoglobin $(\mathrm{mg} / \mathrm{dL})$ & -3.2 & 1.3 & 0.018 & $(-5.9--0.6)$ \\
\hline
\end{tabular}

Residual analysis: $p=0.829$ (Shapiro-Wilk); SCT: Star cancellation task.

Table 5. Correlation between MCV and scores on tests of unilateral spatial neglect.

\begin{tabular}{ccccc}
\hline & & LCT & SCT & LBT \\
\hline MCV & $r$ & -0.089 & 0.001 & 0.063 \\
& $p$ & 0.616 & 0.997 & 0.723 \\
\hline
\end{tabular}

MCV: Mean corpuscular volume; LCT: Line cancellation task; SCT: Star cancellation task; LBT: Line bisection task.

and that this relation is associated with increased penumbra area and cerebral infarct?

Although the $\mathrm{Hb}$ level demonstrated an association the all USN tests, it was weakly correlated with LBT, because the latter test has a relatively poor sensitivity for detecting USN. The other tests applied (LCT and SCT) are generally the most sensitive in perceptual disorders ${ }^{18,19}$. This information is important because the association between $\mathrm{Hb}$ and
LBT can be influenced by the sensitivity of the test to detect USN.

The results of MCV did not show a statistical correlation with performance on NSU tests. In a descriptive analysis of our data, the patients with macrocytic anaemia presented worse performance on tests of cancelling of lines and stars. This datum has been little explored in the literature, where worsening has been reported only in patients with a deficit in the spatial attention network and cognitive decline in patients with macrocytic anaemia ${ }^{20,21}$. This finding presents little consistency with our study in which only 4 patients presented macrocytic anaemia.

The limitations of the present study were small sample size, the fact that individuals could have received electrolyte replacement therapy, and other confounding factors, such as tobacco smoking, poor dietary habits or nutrition status. However, our results not only consistently demonstrate a negative association between $\mathrm{Hb}$ and USN severity, but also demonstrate the importance of the research objective of establishing ideal haemoglobin levels in the acute phase to avoid cognitive and perceptual decline and improve functional prognosis. We recommend that longitudinal followup studies be performed to observe long-term functional outcome and verify whether USN is reduced with haemoglobin replacement.

Based on the results, we conclude that low hemoglobin levels may indicate a worse performance in USN cancellation and bissection tests in acute phase of stroke. Further studies are needed with the inclusion of new confounding factors.

\section{References}

1. Hao Z, Wu B, Wang D, Lin S, Tao W, Liu M. A cohort study of patients with anemia on admission and fatality after acute ischemic stroke. J Clin Neurosci. 2013;20(1):37-42. http://dx.doi.org/10.1016/ j.jocn.2012.05.020

2. Tanne D, Molshatzki N, Merzeliak O, Tsabari R, Toashi M, Schwammenthal Y. Anemia status, haemoglobin concentration and outcome after acute stroke: a cohort study. BMC Neurol. 2010;10(4):22. http://dx.doi.org/10.1186/1471-2377-10-22

3. Gottesman RF, Bahrainwala Z, Wityk RJ, Hillis AE. Neglect is more common and severe at extreme haemoglobin levels in right hemispheric stroke. Stroke. 2010;41(8):1641-5. http://dx.doi.org/ 10.1161/STROKEAHA.110.585265

4. Kimberly WT, Wu O, Arsava EM, Garg P, Ji R, Vangel M et al. Lower haemoglobin correlates with larger stroke volumes in acute ischemic stroke. Cerebrovasc Dis Extra. 2011;1(1):44-53. http://dx.doi.org/ 10.1159/000328219

5. Sico JJ, Concato J, Wells CK, Lo AC, Nadeau SE, Williams LS et al. Anemia is associated with poor outcomes in patientes with less severe ichemic stroke. J Stroke Cerebrovasc Dis. 2013;22(3):271-8. http://dx.doi.org/10.1016/j.jstrokecerebrovasdis.2011.09.003

6. Kellert L, Martin E, Sykora M, Bauer H, Gussmann P, Diedler J et al. Cerebral oxygen transport failure?: decreasing haemoglobin and hematocrit levels after ischemic strokepredict poor outcome and mortality: STroke: RelevAnt Impact of haemoGlobin, Hematocrit and Transfusion (STRAIGHT): an observational study. Stroke. 2011;42(10):2832-7. http://dx.doi.org/10.1161/STROKEAHA.110.606665

7. Kimberly WT, Wu O, Arsava EM, Garg P, Ji R, Vangel M et al. Lower haemoglobin correlates with larger stroke volumes in acute ischemic stroke. Cerebrovasc Dis Extra. 2011;1(1):44-53. http://dx.doi.org/ 10.1159/000328219

8. KurellaTamura M, Wadley VG, Newsome BB, Zakai NA, McClure LA, Howard $G$ et al. Haemoglobin concentration and cognitive impairment in the renal REasons for Geographic And Racial Differences in Stroke (REGARDS) Study. J Gerontol A Biol Sci Med Sci. 2010;65(12):1380-6. http://dx.doi.org/10.1093/gerona/glq126

9. Shah RC, Wilson RS, Tang Y, Dong X, Murray A, Bennett DA. Relation of haemoglobin to level of cognitive function in older persons. Neuroepidemiology. 2009;32(1):40-6. http://dx.doi.org/10.1159/ 000170905

10. Hare GM. Anaemia and the brain. Curr Opin Anaesthesiol. 2004;17(5):363-9.

11. Metry G, Wikström B, Valind S, Sandhagen B, Linde T, Beshara S et al. Effect of normalization of hematocrit on brain circulation and metabolism in hemodialysis patients. J Am Soc Nephrol. 1999;10(4):854-63. 
12. Albert ML. A simple test of visual neglect. Neurol. 1973;23(6):658-64.

13. Schenkenberg T, Bradford DC, Ajax ET. Line bisection and unilateral visual neglect in patients with neurologic impairment. Neurol. 1980;30(5):509-17. http://dx.doi.org/10.1212/WNL.30.5.509

14. Halligan PW, Burn JP, Marshall JC, Wade DT. Visuo-spatial neglect: qualitative differences and laterality of cerebral lesion. J Neurol Neurosurg Psychiatry. 1992;55(11):1060-8. http://dx.doi.org/10.1136/ jnnp.55.11.1060

15. World Health Organization. Nutritional anaemias: report of a WHO Scientific Group. Geneva: World Health Organization; 1968. (Technical report series; vol 405)

16. Bross MH, Soch K, Smith-Knuppel T. Anemia in older persons. Am Fam Physician. 2010;82(5):480-7.
17. Ismailov RM. Cognitive decline in the stroke belt and erythropoietin. Ann Neurol. 2013;73(1):146. http://dx.doi.org/10.1002/ana.23801

18. Agrell BM, Dehlin OI, Dahlgren CJ. Neglect in elderly stroke patients: a comparison of five tests. Psychiatry Clin Neurosci. 1997;51(5):295300. http://dx.doi.org/10.1111/j.1440-1819.1997.tb03201.x

19. Ferber S, Karnath HO. How to assess spatial neglect: line bisection or cancellation tasks? J Clin Exp Neuropsychol. 2001;23(5):599-607. http://dx.doi.org/10.1076/jcen.23.5.599.1243

20. Kaferle J, Strzoda CE. Evaluation of macrocytosis. Am Fam Physician. 2009;79(3):203-8.

21. Gamaldo AA, Ferrucci L, Rifkind J, Longo DL, Zonderman AB. Relationship between mean corpuscular volume and cognitive performance inolder adults. J Am Geriatr Soc. 2013;61(1):84-9. http://dx.doi.org/ 10.1111/jgs.12066 